Article

\title{
Determination of Influencing Factors on Interface Strength of Additively Manufactured Multi-Material Parts by Material Extrusion
}

\author{
Raphael Freund *, Hagen Watschke ${ }^{\mathbb{D}}$, Julius Heubach and Thomas Vietor \\ Institute for Engineering Design, Technische Universität Braunschweig, 38106 Brunswick, Germany; \\ h.watschke@tu-braunschweig.de (H.W.); j.heubach@tu-braunschweig.de (J.H.); \\ t.vietor@tu-braunschweig.de (T.V.) \\ * Correspondence: r.freund@tu-braunschweig.de; Tel.: +49-531-391-3336
}

Received: 29 March 2019; Accepted: 25 April 2019; Published: 29 April 2019

check for updates

Featured Application: The proposed design rules pose an effective way to support the design of multi-material parts for material extrusion.

\begin{abstract}
Material composition complexity offered by material extrusion additive manufacturing offers new opportunities for function-driven part design. Nevertheless, since influencing factors on the interface strength between different materials are not well understood, this complexity is only used infrequently, in part, in design thereby restraining innovation. This paper proposes a systematical approach for identification and quantification of relevant adhesion phenomena that influence interface strength. For this reason, suited test specimen, which utilize the geometric freedom offered by additive manufacturing, are developed for roll peeling tests and peeling resistance of several combinations of rigid and flexible materials is determined. The results show that material choice especially regarding polarity as well as mechanical interlocking in regards to surface roughness and design features have high influence on the interface strength of multi-material parts manufactured by material extrusion. These results are explained through the relevant adhesion mechanisms that determine the interface strength in additively manufactured parts. Finally, criteria that predominantly affect interface strength are deduced and design recommendations for creating functional parts with ill-fitting material combinations are formulated.
\end{abstract}

Keywords: design for additive manufacturing; adhesion theories; multi-material additive manufacturing; material extrusion; polymers

\section{Introduction}

Additive manufacturing (AM) offers new design freedom and thereby high potential for function-oriented part design. Apart from potential geometric complexity achievable only through additive manufacturing, complexity in material composition can be utilized through combination of different materials or material classes. Combining functional materials with standard materials in the same process gives opportunity for the implementation of new features, which would be impossible to realize conventionally. For instance, combination of elastic and stiff materials can be used for the integration of acoustic functions [1], while integration of functional materials like shape memory polymers or conductive polymers can be used for a variety of different applications [2-6].

Albeit, in order to design multi material parts for AM efficiently, detailed knowledge of the interface strength on the boundary layer between materials is vital in order to assure a sufficiently strong bonding of the two faces. While some sources rudimentarily show compatibility of different 
material combinations, the influencing factors on compatibility have not been examined thoroughly. For instance, the website of printer manufacturer Ultimaker B.V. (Geldermalsen, Netherlands) shows compatibility in an incomplete table, which does not provide reasons for good or bad compatibility between materials. In addition, the evaluation of materials' compatibilities is limited to combinations of building and support materials [7].

On simple blunt interfaces, adhesion is the sole phenomenon by which forces can be transmitted, however, a variety of different mechanism based on diffusion, mechanical interlocking, surface energy, chemical bonding, polarity, electrostatics, and interface imperfections have varying influence on adhesion strength [8].

Thus, in order to optimize part design and process parameters for specific material combinations, the relevant adhesion phenomena need to be identified and their influence on the total adhesive force quantified thoroughly. For this purpose, a systematic approach for optimization of interface strength is necessary to fuel innovation via design freedom of additive manufacturing, in particular regarding functional integration enabled by combining multiple materials. Accordingly, effects of different design measures on the quality of layer bonding are to be determined for selected material combinations. Additionally, apart from influences stemming from the choice of materials, process parameters have a huge impact on the strength of the resulting interface and can be used as levers to improve bonding. Furthermore, AM provides a large design freedom with regard to interlocking features due to its layer by layer material application.

\section{Multi-Material Additive Manufacturing and Adhesion Phenomena}

This section gives an overview of the principle of material extrusion, state of the art of multi-material additive manufacturing as well as influencing factors on interface strength of multi-material parts stemming from the adhesion theory.

\subsection{Multi Material Additive Manufacturing in Science and Technology}

Material Extrusion (MEX) is an AM process that utilizes extrusion of thermoplastic polymers to fabricate a part layer by layer. For this purpose, pre-product in the form of a wire, called filament, is conveyed into an extruder, where it is heated until plastification and applied onto the previous layer. Other names for this process include fused deposition modeling (FDM, trademark of Stratasys) and fused filament fabrication (FFF) $[9,10]$. As can be deduced from Figure 1, combination of materials even in the same layer is easily possible with MEX by use of several extrusion nozzles. Therefore, MEX is predestined for multi-material additive manufacturing (MMAM). Hence, manufacturing of specimens is confined to MEX in this publication. Nevertheless, most results can be transferred to other AM processes.

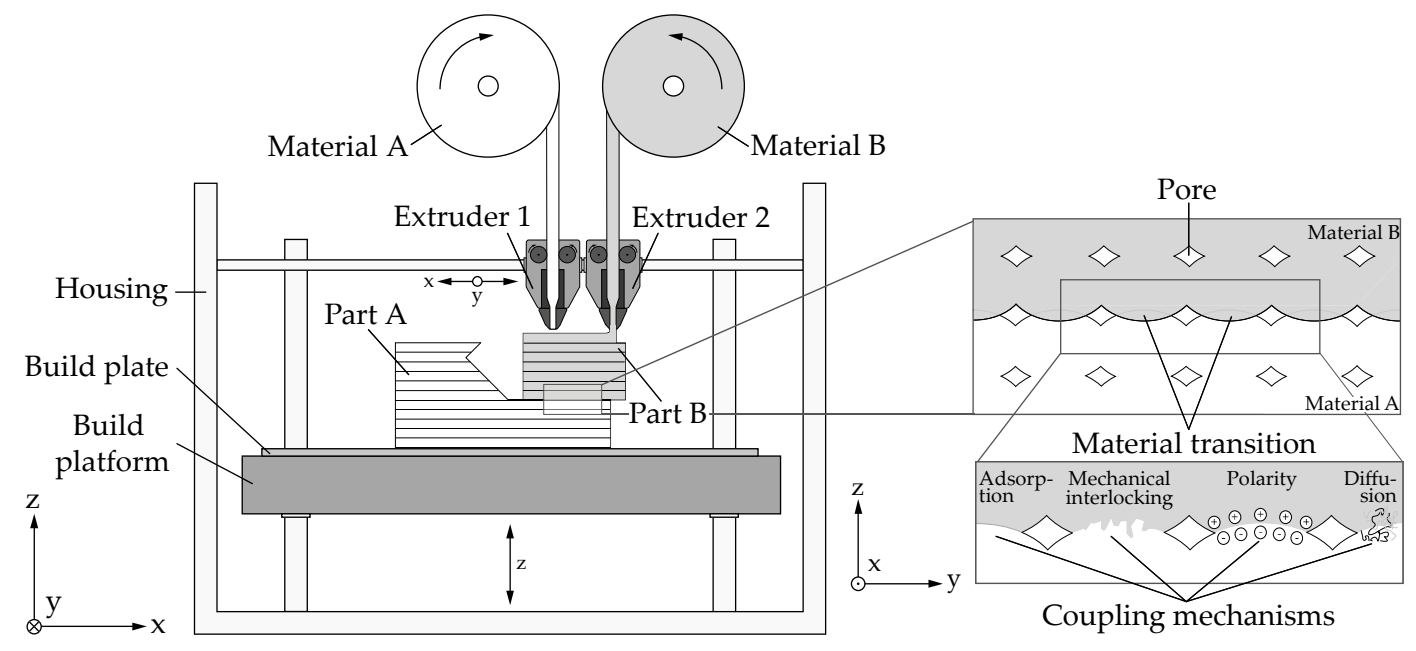

Figure 1. Schematic diagram of material extrusion principle and relevant adhesion mechanisms [11]. 
MMAM can be categorized into discrete multiple materials, composite materials and porous materials. It is an effective way to increase performance of parts by utilizing material complexity offered by additive manufacturing. Especially combination of functional materials with conventional build materials has high potential for future applications. Strategic attachment of materials with different properties like thermal or electrical conductivity, hardness, temperature resistance, etc., allows for integration functions and reduction of parts [12].

Acoustic functions via combination of elastic and stiff materials by material extrusion have been proposed in literature [1]. Furthermore, a way to realize functions by combining conventional materials with shape memory polymers via vat polymerization has been shown as well [2,5]. Moreover, integration of conductive structures via MEX has been shown to be possible and can be utilized to produce heat radiant surfaces $[3,4,6,13]$.

Since MMAM offers a multitude of new design potentials, designers need to be aided in their decision-making regarding material choice, machine operation and part design [14-17]. Hence, this publication aims to give recommendations for this decision making process.

\subsection{Influencing Factors on Interface Strength}

Influencing factors on interface strength of multi material parts manufactured by AM are diverse and therefore going into detail on all of them in this publication would lead to far. Apart from combination of materials, geometry of the printed part, process parameters during printing, additional pre-treatment steps, and environmental conditions show influence on bonding strength and thermal stresses [18-20]. Figure 2 shows an overview of possible influencing factors on interface strength and emphasizes those focused on in this paper.

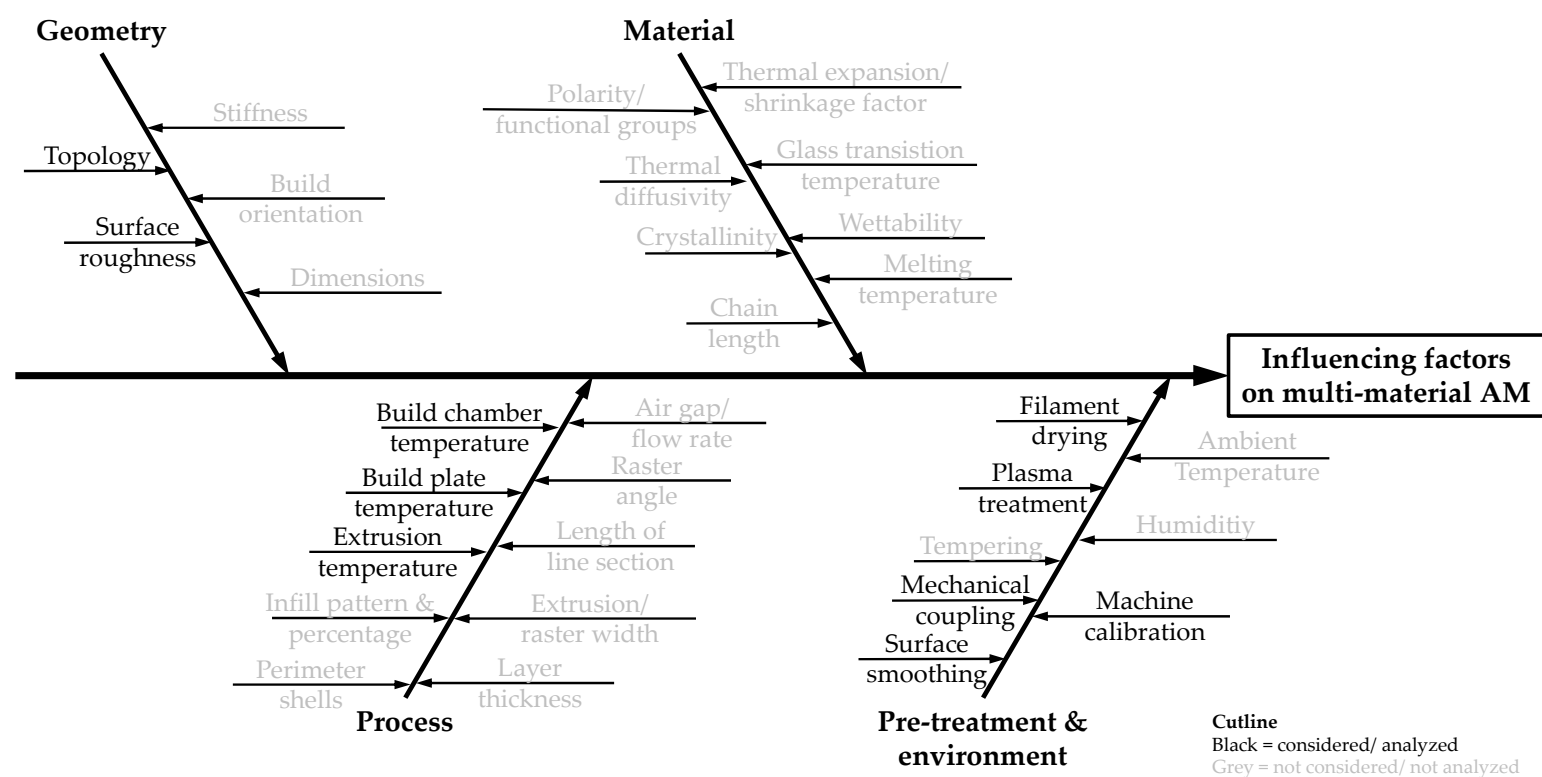

Figure 2. Fishbone diagram of possible influencing factors on interface strength of multi material AM based on References [8,21]. Enhanced by material-specific, geometrical, process-specific, and pre-treatment factors.

Each of the influencing factors shown in Figure 2 can be ascribed to a specific mechanism of adhesion to more thoroughly understand the underlying reason for the influence on the interface. The entirety of those phenomena is called adhesion theory and gives a measurement of interface strength between different materials as well as layers of the same material. Mechanisms of adhesion are illustrated in Figure 3 and are explained in detail later on. Since all adhesion mechanisms take effect at the same time, the extent of influence of each phenomenon specifically is very hard to determine, especially since changes in process parameters often affect several mechanisms at once. For example, 
while an increase in extrusion temperature may lead to enhanced diffusion, higher temperatures can also decrease viscosity of the molten material as described by the Williams-Landel-Ferry Equation [22]. This, in turn, may affect mechanical adhesion, since less viscous material might be able to more efficiently fill the voids of the already printed layers before solidification.

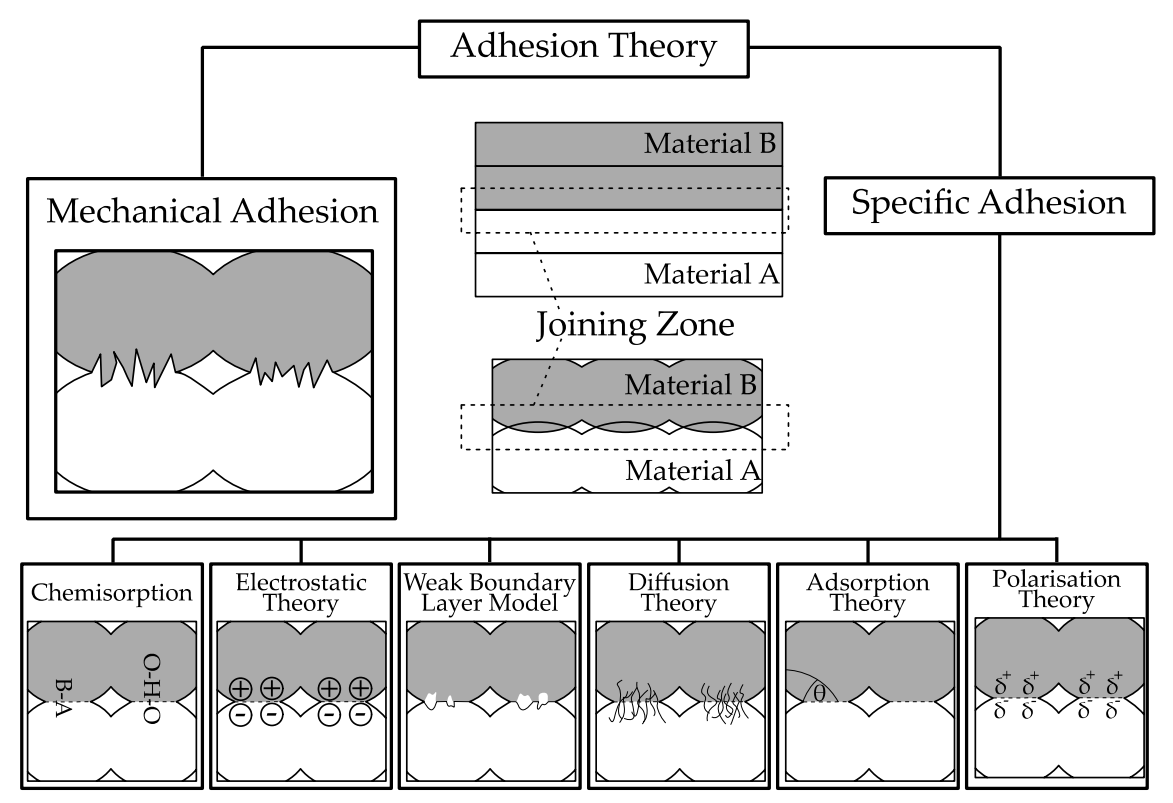

Figure 3. Schematic diagram of adhesion mechanisms. Based on $[8,18]$.

In order to gain a better understanding of the process of multi-material MEX and the relevant levers for achieving good layer bonding, an understanding of the underlying physical principle of adhesion is crucial.

\subsubsection{Mechanical Adhesion}

Mechanical adhesion is rooted in the microscopic interlocking of the different phases coming in contact with each other at the interface zone. This phenomenon can only occur if liquid material solidifies inside the depressions of a porous material. Since having relatively high surface roughness lies in the nature of additive manufacturing, one would expect mechanical adhesion to play a relatively major role in the strength of layer bonding. However, even though each layer might have high roughness due to the infill pattern, the second material needs to be able to fill the resulting depression before solidifying, for high roughness to have a positive effect on mechanical adhesion. The better the microscopic pores are filled, the higher the overlapping surface, enhancing other adhesion mechanisms. Additionally, better filled voids mean better mechanical interlocking, while partial filling of depressions leads to pores on the interface which has negative influence on adhesive strength. For this reason, mechanical adhesion is predicted to depend heavily on the flow-ability of the molten material. Furthermore, surface roughness due to extrusion width, infill pattern and percentage, extrusion temperature, build orientation and other process parameters is expected to have high influence on mechanical adhesion [23-26].

\subsubsection{Polarization Theory and Chemisorption}

If both materials are polar in nature, adsorption is increased by the influence of Van der Waals forces between the two phases. Moreover, if both phases show the ability to form hydrogen bonds (HB) this effect is even higher, since the strength of the interaction in this case is even stronger. However, the most frequently used materials used for MEX show little prospect for forming strong intermolecular interactions. Polylactide (PLA) and acrylonitrile butadiene styrene (ABS) for example, even though 
rather polar, cannot form HBs for lack of highly polar bonded hydrogen. Chemisorption on the other hand describes the process of increasing adhesion by formation of chemical bonds between the two phases. Regarding AM chemisorption usually only occurs in resin-based methods like vat polymerization. Since MEX exclusively processes thermoplastic polymers, chemisorption usually does not occur $[27,28]$.

There are very limited ways to change the magnitude of these two adhesion mechanisms for a given material combination. Modifying the surface of the solid material by plasma treatment activates the surface by inserting functional groups into the polymer chain, thereby changing polarity [29]. Even more, radicalization of the molecules by plasma can induce formation of chemical bonds between different phases by radicalization or functionalization of polymer chains. However, this effect is very time dependent, since the inserted groups and radicals quickly degrade over time-in the scale of seconds-which makes this mechanism negligible for the purpose of MEX. Still, plasma treatment is an effective way to increase adhesion and has been used in multi material die casting for many years $[27,28]$.

\subsubsection{Adsorption Theory}

In order for intermolecular forces to have any effect, the distance between molecules needs to be small. Therefore, high wettability plays an important role in achieving good adhesion. Wettability strongly depends on the surface tension of the used materials and can therefore be modified only in very limited fashion. Functionalization of the surface via plasma treatment once again is an effective way to increase wettability. The functional groups inserted into the polymer change surface tension and thereby wettability, effectively enhancing adhesion $[23,28]$.

\subsubsection{Diffusion Theory}

This theory describes the formation of material locking by inter diffusion. This phenomenon can only occur, if both partners show affinity to each other and in the case of inter diffusing polymers is highly dependent on the mobility of polymer chains. For that reason, since chain mobility is largely influenced by chain length as well as thermal factors, this mechanism is mainly driven by time and temperature. Bringing more thermal energy into the system, e.g., by lowering the printing speed, should theoretically allow for more inter diffusion and thereby stronger adhesion $[28,30]$.

\subsubsection{Weak Boundary Layer Model}

The weak boundary layer model refers to the weakening of adhesion due to imperfections at the interface. Due to for example air pockets or impurities at the boundary, the area of overlap is smaller and the impact of other adhesion mechanisms is reduced. The magnitude of this model however is disputed in literature. Therefore, it will not be discussed in detail in this publication either [28,31].

\subsubsection{Electrostatic Theory}

Electrostatic theory describes the process of enhanced adhesion through formation of an electric double layer at the interface. In this double layer, electrostatic forces are responsible for holding the partners together. Since this requires the existence of mobile load carriers, which do not exist abundantly in most thermoplastics, the effects of this model are expected to be minimal in the case of multi material MEX [28,32].

\section{Experimental}

In order to examine the possibility of applying adhesion mechanisms onto multi-material design for additive manufacturing, specimens for several material combinations are fabricated via material extrusion. Additionally, selected material combinations are additionally subjected to plasma or heat treatment before the application of the second material occurs. In order to demonstrate the effect of 
smart design on the interface, one material combination is furthermore fitted with interlocking features to enhance bonding strength. Finally, roll peeling tests are conducted on all specimens. In total, seven different material combinations are tested.

\subsection{Experimental Set-Up and Additive Manufacturing of Specimens}

In this contribution, the interface strength and the related influencing factors of different material combinations are examined on the basis of a rigid and a flexible material. Previously developed test specimens for the characterization of multi-material parts manufactured by MEX solely consider combinations of two rigid materials [11]. Thus, a test specimen for such material combinations of a rigid and flexible part is developed in accordance with DIN EN 1464 that is originally used for the determination of peel resistance of adhesive bonds [33]. Figure 4 shows the specimen in isometric view (a) and including size specifications (b). In order to facilitate the separating process of the different parts of the test specimen for clamping initially, a honeycomb structure is incorporated in the front area $\left(60 \times 25 \mathrm{~mm}^{2}\right)$. Thus, the resulting joining zone that is used for the determination of the interface strength has a length of $100 \mathrm{~mm}$.

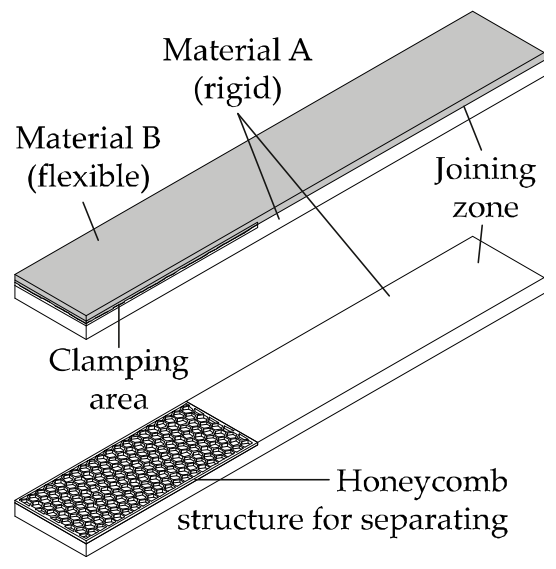

(a)

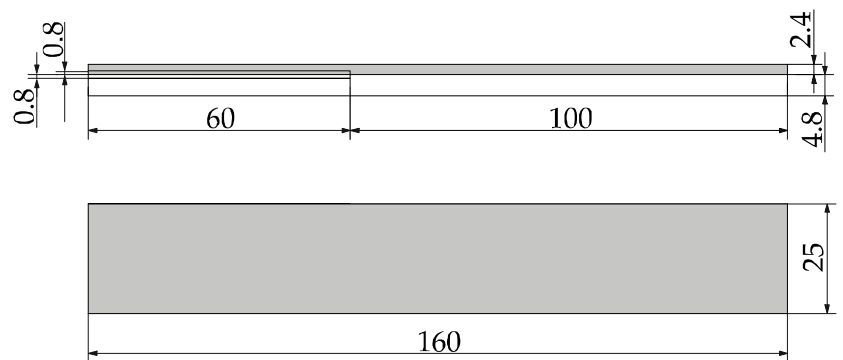

(b)

Figure 4. (a) Isometric view and (b) size specifications of the utilized test specimen.

Table 1 gives an overview of the examined material combination. In total, six different rigid and two different flexible materials are tested in the experimental studies. All specimens are manufactured by using the same raster angle orientation $\left( \pm 45^{\circ}\right)$, layer thickness $(0.2 \mathrm{~mm})$, and number of perimeter shells (2) in order to ensure comparability of the results.

Table 1. Selective material properties and utilized process parameters for the manufacturing of the multi-material test specimens.

\begin{tabular}{|c|c|c|c|c|c|}
\hline Type & Material & Manufacturer & $\begin{array}{c}\text { Glass } \\
\text { Transition }\end{array}$ & $\begin{array}{c}\text { Nozzle } \\
\text { Temperature }\end{array}$ & $\begin{array}{l}\text { Tested Material } \\
\text { Combinations }\end{array}$ \\
\hline \multirow{5}{*}{ Rigid } & PLA [34] & DAS FILAMENT & $55-60^{\circ} \mathrm{C}$ & $215^{\circ} \mathrm{C}$ & NinjaFlex®, TPU-93 \\
\hline & ABS [35] & Innofil B.V. & $105^{\circ} \mathrm{C}$ & $245^{\circ} \mathrm{C}$ & NinjaFlex®, TPU-93 \\
\hline & XT [36] & colorFabb & $75^{\circ} \mathrm{C}$ & $245^{\circ} \mathrm{C}$ & NinjaFlex® \\
\hline & XT-CF20 [37] & colorFabb & $80^{\circ} \mathrm{C}$ & $245^{\circ} \mathrm{C}$ & NinjaFlex® \\
\hline & GF30-PA6 [38] & XSTRAND $^{\mathrm{TM}}$ & $\mathrm{n} / \mathrm{a}$ & $270^{\circ} \mathrm{C}$ & NinjaFlex® \\
\hline \multirow[t]{2}{*}{ Flexible } & NinjaFlex®[39] & NinjaTek & $-35^{\circ} \mathrm{C}$ & $230^{\circ} \mathrm{C}$ & $\begin{array}{c}\text { PLA, ABS, XT, } \\
\text { XT-CF20, GF30-PA6, } \\
\text { GF30-PP }\end{array}$ \\
\hline & TPU-93 [40] & German RepRap & $\mathrm{n} / \mathrm{a}$ & $210^{\circ} \mathrm{C}$ & PLA, ABS \\
\hline
\end{tabular}


For the manufacturing of the specimens, the pro-consumer machine X400 by German RepRap $\mathrm{GmbH}$ (Feldkirchen, Germany) with a dual system is used. The preparation of the build job is carried out with the slicing software Simplify3D, version 4.0. The rigid part is processed on a heated build platform consisting of a glass plate with material-specific adhesion if required, for example, Kapton tape for GF30-PA6, and PP tape for GF30-PP. The flexible part is directly printed onto the rigid part after a cleaning process is performed in order to avoid material residues and, thus, defects at the joining zone. For both materials, the nozzle diameter is kept at $0.4 \mathrm{~mm}$ at all times and orientation angles of infill lines have not been varied throughout the experiment. The calibration set-up is kept constant throughout specimen fabrication.

Before specimen manufacturing, the materials are dried individually. To ensure equal environmental conditions during the printing process, the filaments are directly processed from a filament storage box that regulates relative humidity at about $20 \%$. Before testing, all specimens are stored at $23 \pm 1{ }^{\circ} \mathrm{C}$ ambient temperature and a relative humidity of $45-50 \%$ for at least one week in the laboratory.

As shown in Figure 5 manufacturing of specimens needs to be conducted under very precise conditions in order to assure applicable test results. Since both used TPUs show low flexural rigidity, bulging of the filament under compressive load after passing the direct extruder is a common problem. Furthermore, low wettability may lead to an irregular interface, thereby tainting results.

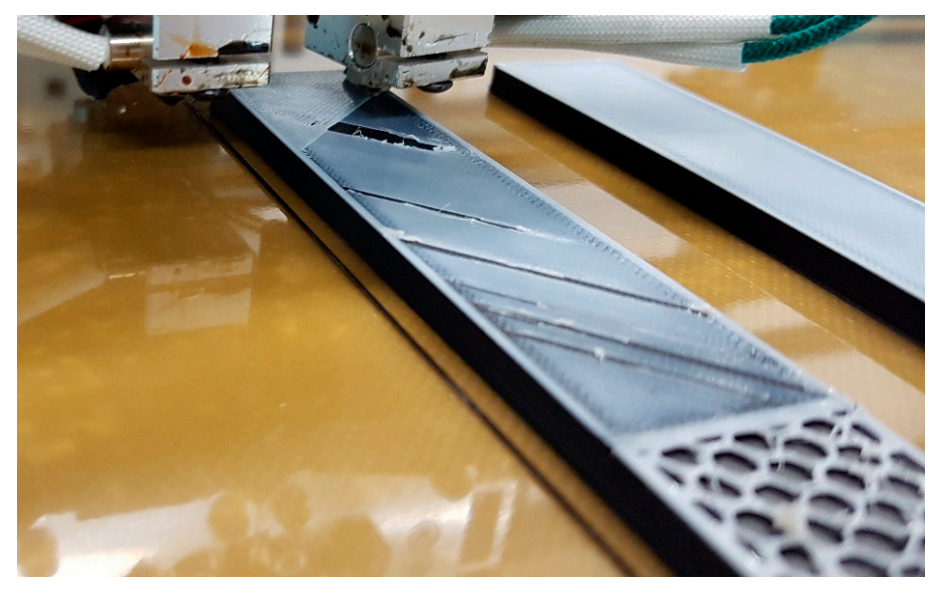

Figure 5. Extrusion problems during manufacturing of specimens due to imprecise leveling.

On top of that, leveling of the two nozzles is crucial in attaining good interface bonding. If the second nozzle initially is too far away from the last layer of the first material, the bonding at the interface is very low which naturally leads to very low peeling resistance. On the other hand, if the second nozzle is leveled too low extrusion resistance is too high and bulging is unavoidable. Figure 6 shows this phenomenon exemplarily for the combination of PLA and ABS. While the badly leveled specimen on the left shows no signs of discoloration after breaking, the interface of the well-leveled specimen on the right shows discolorations on both sides of the interface. These stem from higher transmitted stress at the interface and prove that leveling needs to be kept constant during manufacturing of specimen in order to not affect test results.

In order to determine the influence of additional measures to increase the interface strength, plasma treatment (Section 3.2) is applied to the combinations PLA/NinjaFlex and PLA/TPU-93 and in situ smoothing (Section 3.3) was performed for the combination PLA/NinjaFlex.

Additionally, to evaluate the potential of geometric freedom offered by AM for strengthening of the interface apart from simple specimens that show a strictly horizontal interface, specimens with added interlocking features were produced out of PLA and NinjaFlex. 


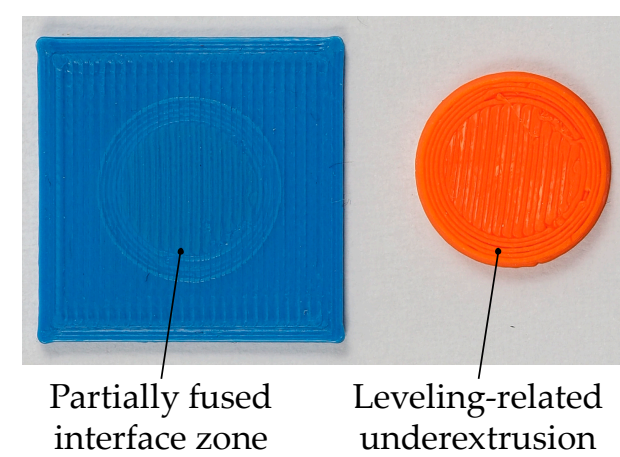

(a)

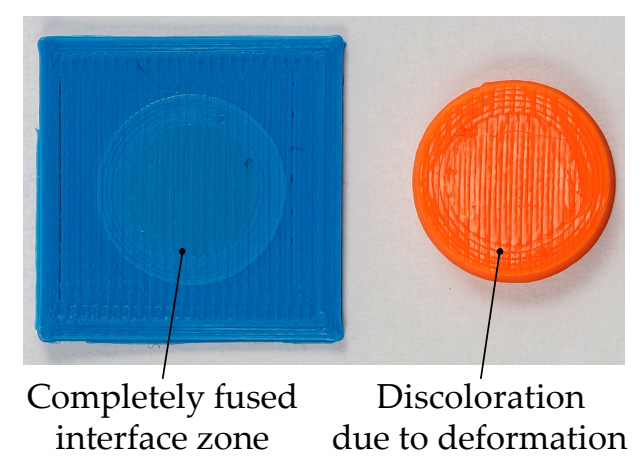

(b)

Figure 6. Difference between a badly leveled (a) and a well-leveled (b) interface zone for the combination of PLA (blue) and ABS (orange).

\subsection{Plasma Treatment}

The standard process parameter setting is used for the pretreatment with atmospheric pressure plasma of the PLA specimens: the distance between plasma jet and treated substrate is chosen as 10 $\mathrm{mm}$ and the speed is set to $50 \mathrm{~mm} / \mathrm{s}$. The experimental set-up and the plasma treatment are shown in Figure 7. A plasma jet of the Plasmatreat $\mathrm{GmbH}$ (Steinhagen, Germany) is used.

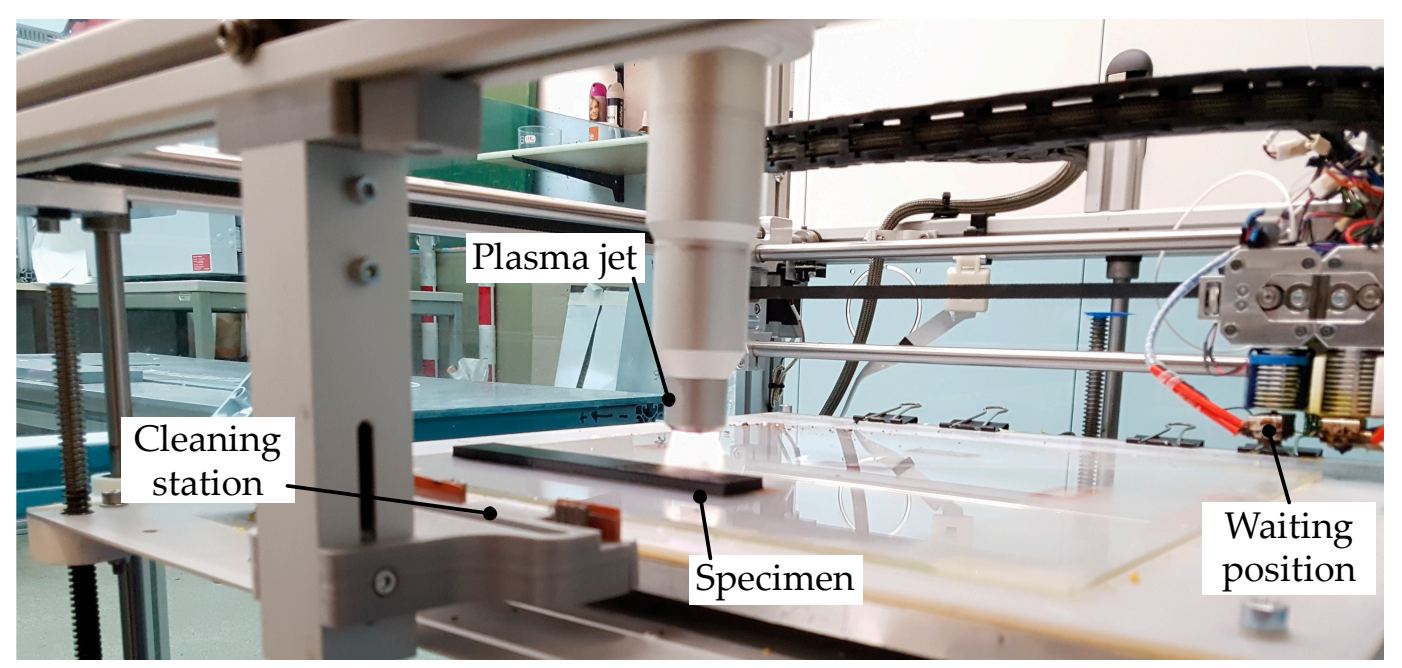

Figure 7. Robot-based plasma pretreatment of the lower part of the specimen before applying of the second material.

\subsection{Smoothing}

In situ surface smoothing is accomplished by heating the top layer of the PLA specimen before change of material. For this purpose, as part of the tool change script, the first nozzle is kept at extrusion temperature of $215^{\circ} \mathrm{C}$. Furthermore, in order to avoid any unwanted extrusion during the smoothing process, the filament is retracted and any further movement of the stepper motor is prevented. Subsequently, the nozzle is automatically cleaned by wiping on a cleaning station consisting of a wire brush and a rubber shield. Then, to achieve smoothing the nozzle, it repeats the exact path of the last layer at a speed of $50 \mathrm{~mm} / \mathrm{s}$, while nozzle temperature is not changed. As can be seen later, this leads to the highest ridges of the structures being torn off by the hot nozzle, effectively smoothing the surface. The profile height is thereby reduced by about $30 \%$. 


\subsection{Roll Peeling Tests}

For the mechanical testing a zwickiLine of the ZwickRoell GmbH \& Co. KG (Ulm, Germany) with a $1 \mathrm{kN}$ load cell is used. The clamping length is $60 \mathrm{~mm}$. The tests are performed at $23 \pm 1{ }^{\circ} \mathrm{C}$ ambient temperature, a relative humidity of $45 \pm 5 \%$, and a constant testing speed of $50 \mathrm{~mm}$ per minute. This amounts to half the speed defined in the norm. A picture during testing is shown in Figure 8.
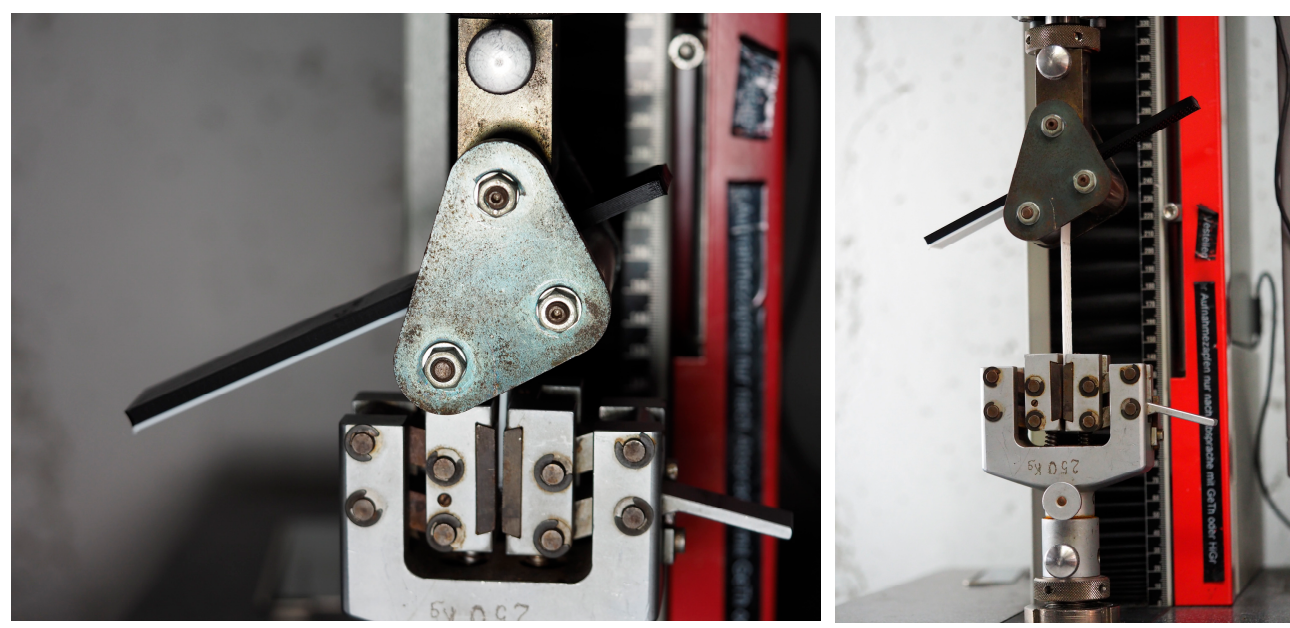

Figure 8. Depiction of roll peeling tests.

\subsection{Microscopy}

In order to determine roughness, some rectangular specimens with dimensions $20 \times 25 \times 2 \mathrm{~mm}$ are produced with the same machine calibrations as the roll peeling specimens and are examined under a confocal laser scanning microscope VK 9710 produced by Keyence Deutschland GmbH (Neu-Isenburg, Germany). Images are taken with a magnification of 10 and vertical increments of $0.1 \mu \mathrm{m}$ from right outside of focus on the lower and upper end of the structure. For each specimen a grid of $3 \times 3$ images was assembled and analyzed as a whole. Each assembly of images was corrected for tilt and filtered with a $3 \times 3$ median mask in order to reduce signal noise. Then maximum profile height $R c$ is measured on three different lines perpendicular to MEX line direction and the arithmetic mean is calculated. Since all roll peeling specimens are fabricated with a $+45^{\circ} /-45^{\circ}$ infill orientation, the measured direction is the same in which material lines of the second material are applied to the interface. Lastly, the mean value of those three measurements is calculated.

\section{Results}

Figure 9 shows an overview of all tested material combinations (see Table 1) without additional treatment or interlocking structures. It can be noted, that peeling resistance varies by about an order of magnitude between the weakest and the strongest material combination.

In the conducted experiment, the combination of materials with the highest interface strength is GF30-PA6 and NinjaFlex with a peeling resistance of about $9.0 \mathrm{kN} / \mathrm{m}$ and fractures occurring exclusively on the adhesive interface. However, since the second strongest combination (ABS and NinjaFlex) showed a substrate fracture on all peeling tests, interface strength in this case can only be deduced to be stronger than the determined value of about $6.0 \mathrm{kN} / \mathrm{m}$. The specimens made out of XT and NinjaFlex showed adhesive fracture at about $5.0 \mathrm{kN} / \mathrm{m}$, while the specimen produced from XT-CF20 and NinjaFlex failed at about the same load of $5.1 \mathrm{kN} / \mathrm{m}$, however, while partly destroying the substrate. The Combination of PLA and NinjaFlex showed a purely adhesive fracture at a load of about $2.4 \mathrm{kN} / \mathrm{m}$. Both combinations containing TPU-93 showed adhesive failure at very low loads of about $0.7 \mathrm{kN} / \mathrm{m}$ (ABS) and $0.1 \mathrm{kN} / \mathrm{m}$ (PLA). 


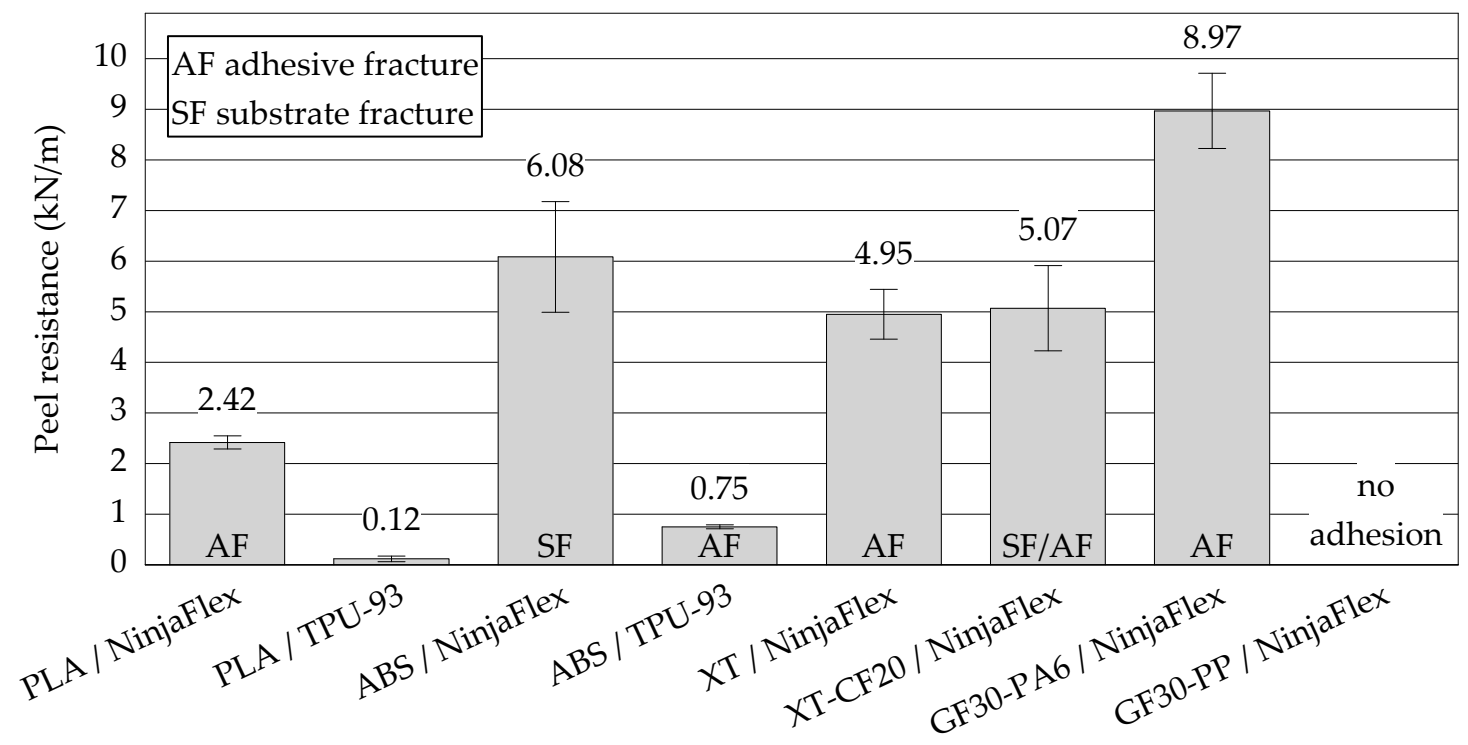

Figure 9. Overview of peel resistance of different material combinations.

Additional measures and their influence on interface strength of PLA are summarized in Figure 10. Some values are identical to the ones in Figure 9 and are only shown again for clarity. It can be seen, that both plasma pretreatment as well as interlocking features have significant influence on the bonding strength, while surface smoothing leads to a reduction of peel resistance.

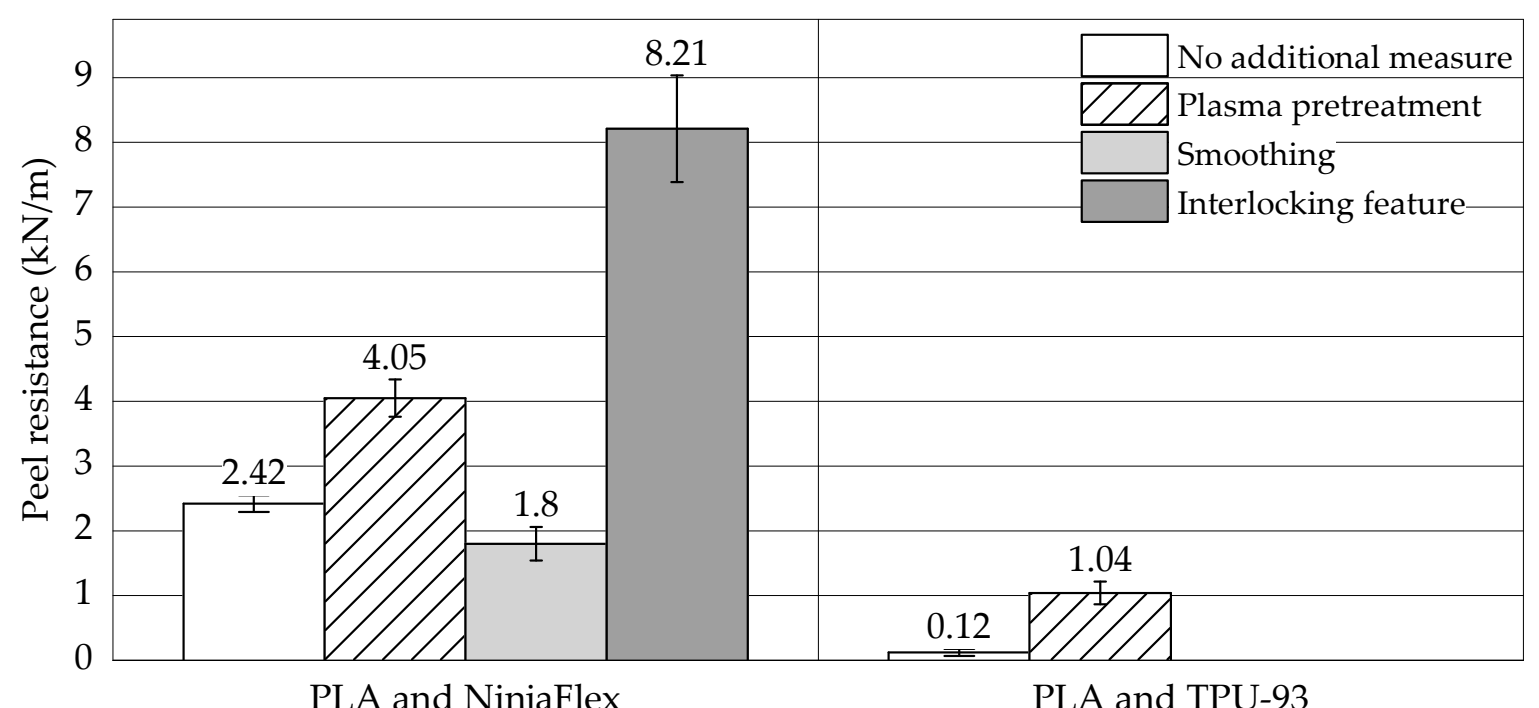

Figure 10. Comparison of different additional measures in order to increase the interface strength of selected material combinations.

\subsection{Mechanical Adhesion}

As can be deduced by comparing peeling resistance of regular PLA/NinjaFlex specimens to ones with interlocking structures, mechanical interlocking has very high influence on adhesion in multi-material MEX. A depiction of a test specimen with these interlocking features can be seen in Figure 11. 


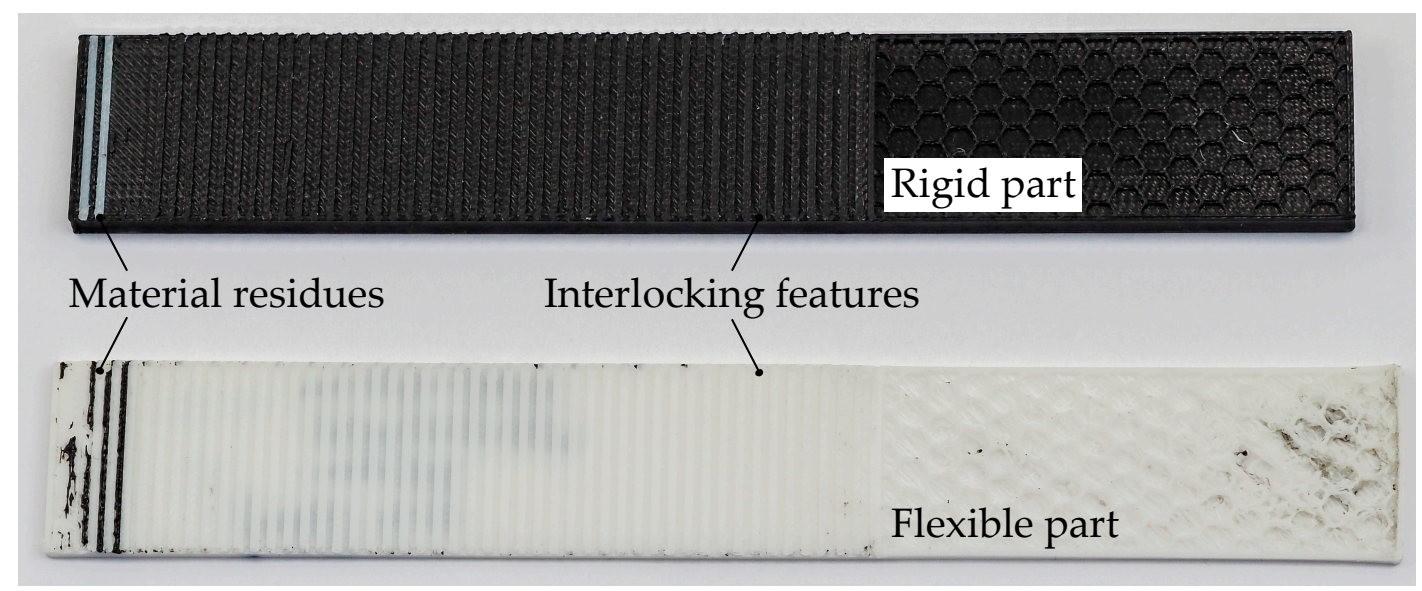

Figure 11. PLA/NinjaFlex specimen with interlocking features after roll peeling tests.

While the unchanged interface only shows a peeling resistance of about $2.4 \mathrm{kN} / \mathrm{m}$ integrating interlocking features results in a peeling resistance that is more than 3 times as high. While the influence of all other adhesion mechanism stays the same for both cases, macroscopic interlocking features enhance mechanical adhesion drastically, as bigger depressions can be filled more easily by molten material. Since machine calibration is not changed, it can be assumed that in this case about $6 \mathrm{kN} / \mathrm{m}$ can be transferred via mechanic adhesion alone. As seen in Figure 11, this heightened bonding strength even results in the tensile strength of both materials being exceeded in some parts of the specimen, which results in noticeable material residues in the very left part of the specimen.

This highlights the advantage of AM over conventional manufacturing techniques. By utilizing the geometric freedom of AM through creating structures not manufacturable by conventional means, adhesion can be highly increased. However, in order to utilize this, a bare minimum requirement for the material combination is that material B needs to be able to wet material A. Otherwise the combination would already fail during the manufacturing process.

On the other hand, it can be seen that surface roughness observably only plays a minor role in mechanical adhesion for multi material MEX. While maximum profile height Rc of the specimen XT with embedded carbon fiber is about $200 \mu \mathrm{m}$ and thereby contrary to expectation more than $70 \mu \mathrm{m}$ smaller than XT without embedded fibers, peel resistance only differs negligibly, as seen in Figure 9.

As can be seen in Figure 12 specimens made out of XT without embedded fibers show deep crevices that even allow view onto the next lower layer. Ideally, those voids could be filled with different material at the layer of interface, creating interlocking features comparable to the ones fabricated out of PLA and NinjaFlex. One would expect those features to improve peel resistance drastically. Since XT with embedded fibers has no such holes, as shown in Figure 12 and therefore no way of forming deep interlocking features, yet peeling resistance is almost identical, one can only conclude that no such structures were formed during fabrication. Possible reasons for this behavior might be that molten NinjaFlex is not mobile enough to fill crevices above a certain depth or below a certain width, meaning higher roughness has no more positive effect. 


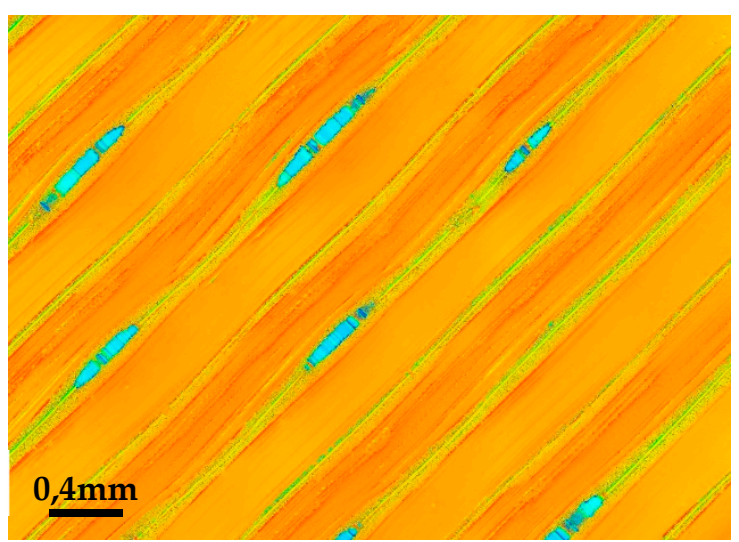

(a)

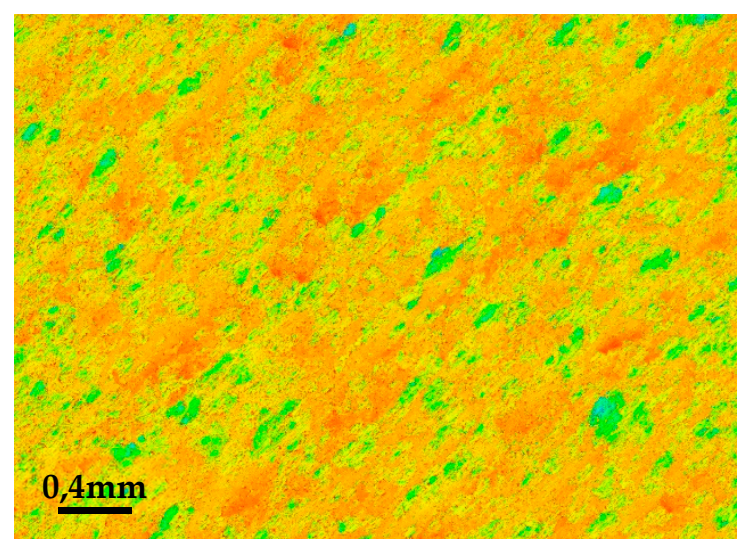

(b)

Figure 12. Height images of regular XT specimens (a) and XT specimens with embedded carbon fiber (b).

On the other hand, peeling resistance of the combination of smoothened PLA and NinjaFlex is lower than that of the regular PLA/NinjaFlex combination. While specimens out of smoothened PLA show a surface roughness of about $26 \mu \mathrm{m}$, the regularly printed specimens have a roughness of about $35 \mu \mathrm{m}$.

Figure 13 shows the process of determining surface roughness exemplarily for regular and smoothed PLA, while the same method of measuring was used for XT. It can be seen that the hot nozzle ripped parts of the structure out of the specimen during the smoothing process, leaving behind smooth plateaus where ridges used to be. Those smooth plateaus on the one hand offer less surface area for other adhesion mechanisms to be effective and on the other hand result in less interlocking features between the materials.

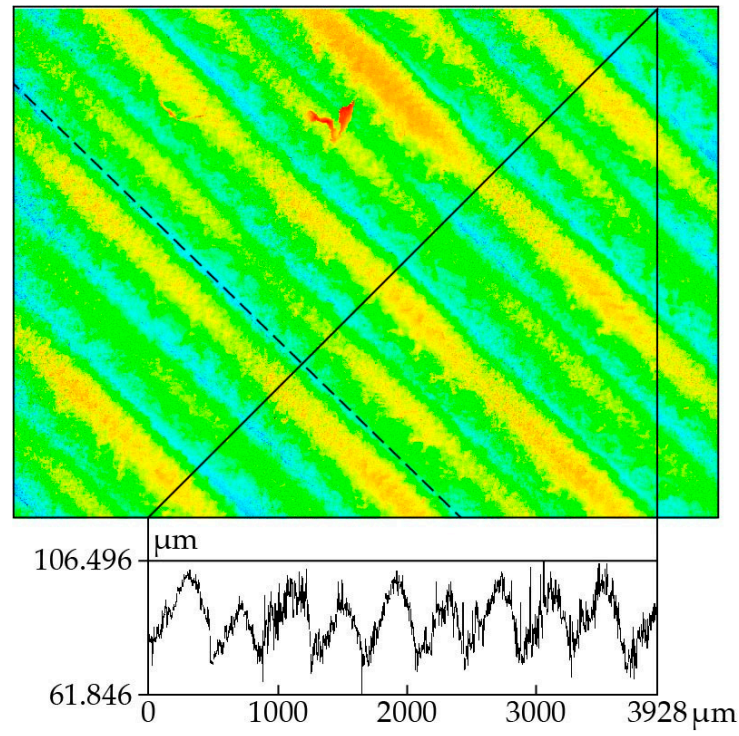

(a)

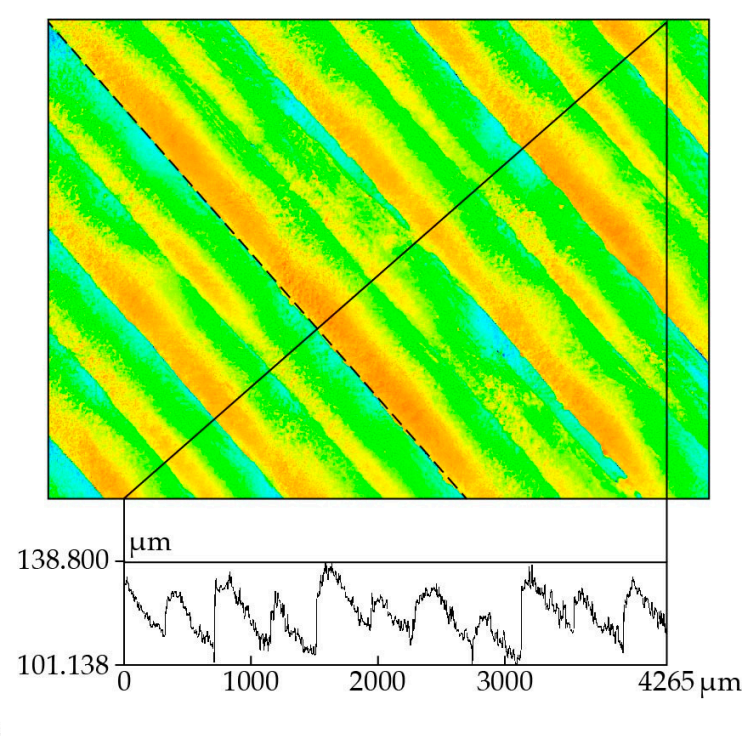

(b)

Figure 13. Height images of regular PLA specimens (a) and smoothened PLA specimens (b).

Hence, peel resistance of the combination of those materials with NinjaFlex are about $1.8 \mathrm{kN} / \mathrm{m}$ for the smoothened specimen and $2.4 \mathrm{kN} / \mathrm{m}$ for the regular specimen respectively as shown in Figure 10. This leads to the conclusion that higher roughness leads to better adhesion only to a certain extent, since viscosity of molten NinjaFlex is too high to fill structures above a certain roughness. Hence, adhesion 
decreases when the surface roughness of the already quite smooth PLA sample is further reduced by about $10 \mu \mathrm{m}$, yet a change of surface roughness by about $70 \mu \mathrm{m}$ for the quite rough XT sample only has minor effect. However, since viscosity lowers with higher temperature, higher extrusion temperatures might be able to increase mechanical adhesion. This is worth examining in further research.

\subsection{Polarity}

It is easily discernible in Figure 9 that the combination of PA6 with embedded glass fibers and NinjaFlex shows the highest peel resistance of the tested combinations. This likely stems from the high polarity of PA6. Even though the exact molecular structures of the used NinjaFlex and TPU-93 are unknown to the authors, infrared spectroscopy shows that the former is based on polyester while the latter has polyether as the main building blocks. Since the molecular structure of PA6 shows both a relatively high density of highly polar bonded hydrogen - as HB donor-and lone pairs of electrons-as HB acceptor-it is capable of forming HBs in the presence of both donors and acceptors, while all other tested rigid materials can only act as HB acceptor. Since both flexible materials can only act as HB acceptor, the high interface strength for the combination GF30-PA6/NinjaFlex very likely stems from the formation of HBs. On the other hand, the structures of PLA and ABS only show HB acceptors, meaning in the absence of donors in the second material the formation of HBs is impossible, drastically reducing adhesion through the polarization theory.

Additionally, while TPU-93 shows polar bonded ester groups along the polymer chain, NinjaFlex contains the more polar ester groups with oxygen attached perpendicular to the polymer chain direction by double bond. Since the effects of polar covalent bonds in the ether group are symmetric they are expected to cancel out more easily, which suggests TPU-93 to be the less polar material, which is presumably the main reason for the significantly better bonding properties of NinjaFlex.

\subsection{Plasma Treatment}

As elaborated in Sections 2.2.2 and 2.2.3 plasma treatment is an effective means of improving adhesion through polarization, chemisorption and adsorption. Even though chemisorption can effectively be neglected regarding our experimental setup a multitude of different mechanisms are still affected by plasma treatment. Furthermore, since heat generation caused by plasma treatment leads to a surface smoothing of specimens, which in turn leads to lower mechanical adhesion, the fractions of influence of different mechanisms are hard to quantify. Nevertheless, it can be seen in Figure 10 that plasma treatment has an immense net positive effect on adhesion for both examined material combinations PLA/NinjaFlex and PLA/TPU-93. While the former demonstrates an increase of peeling resistance by more than $2.2 \mathrm{kN} / \mathrm{m}$ the latter, even though displaying significantly lower adhesion, still shows an increase of peeling resistance by more than $0.9 \mathrm{kN} / \mathrm{m}$. Since adhesion for PLA/TPU-93 specimens was very low in the first place, this corresponds to an increase of peeling resistance of more than $750 \%$.

\subsection{System of Relationships}

Based on these results as well as the adhesion mechanisms discussed in Section 2, bonding strength has been determined to be positively influenced mainly by mechanical adhesion, diffusion, adsorption and polarization, while thermal stresses decrease bonding strength and in the worst case even lead to delamination during the printing process. Therefore, in order to further understanding of the influences on the bonding strength, it is expedient to evaluate all determined levers from Figure 2 on their influence regarding those five categories. The resulting matrix of relationships is depicted in Table 2 and the levers are categorized based on whether the influence has been attested through experiments or deduced from the mechanisms of adhesion. 
Table 2. System of relationships of proposed influencing factors on the most relevant adhesion phenomena and on thermal stresses ( Influence determined experimentally; $\bigcirc$ Proposed influence).

\begin{tabular}{|c|c|c|c|c|c|}
\hline Influencing Factor & $\begin{array}{c}\text { Mechanical } \\
\text { Adhesion }\end{array}$ & $\begin{array}{c}\text { Diffusion } \\
\text { Theory }\end{array}$ & $\begin{array}{c}\text { Adsorption } \\
\text { Theory }\end{array}$ & $\begin{array}{c}\text { Polarization } \\
\text { Theory }\end{array}$ & $\begin{array}{l}\text { Thermal } \\
\text { Stresses }\end{array}$ \\
\hline Process-Specific & & 0 & & & \\
\hline Build Chamber & & & & & \\
\hline Temperature & & ○ & & & $\bullet$ \\
\hline Build Plate Temperature & & $\bigcirc$ & & & $\bullet$ \\
\hline Extrusion Temperature & 0 & 0 & 0 & & $\bullet$ \\
\hline Infill & 0 & & & & 0 \\
\hline Perimeter Shells & 0 & & & & \\
\hline Air Gap & 0 & & & & \\
\hline Flow Rate & 0 & 0 & & & \\
\hline Raster Angle & 0 & & & & 0 \\
\hline Length of Line Section & $\bigcirc$ & & & & $\bigcirc$ \\
\hline Extrusion Width & 0 & & & & 0 \\
\hline Layer Thickness & $\bigcirc$ & $\bigcirc$ & & & $\bigcirc$ \\
\hline \multicolumn{6}{|l|}{ Pretreatment } \\
\hline Filament Drying & $\bullet$ & 0 & $\bigcirc$ & $\bigcirc$ & - \\
\hline Plasma Treatment & • & 0 & 0 & 0 & \\
\hline Tempering & 0 & 0 & & & • \\
\hline Mechanical Coupling & $\bullet$ & & & & \\
\hline Surface Smoothing & • & & & & \\
\hline Ambient Temperature & & & & & $\bigcirc$ \\
\hline Humidity & & & & & $\bigcirc$ \\
\hline Machine Calibration & $\bullet$ & 0 & & & 0 \\
\hline \multicolumn{6}{|l|}{ Material } \\
\hline Polarity & & & $\bigcirc$ & $\bigcirc$ & \\
\hline Thermal Diffusivity & & 0 & & & \\
\hline Chain Length & & 0 & 0 & & \\
\hline Thermal Expansion & & & & & $\bigcirc$ \\
\hline Glass Transition & & 0 & 0 & & 0 \\
\hline Temperature & & J & 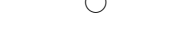 & & 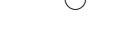 \\
\hline Wettability & $\bigcirc$ & & $\bigcirc$ & & \\
\hline Melting Temperature & & $\bigcirc$ & & & $\bigcirc$ \\
\hline Crystallinity & & 0 & 0 & & $\bigcirc$ \\
\hline Filler & $\bigcirc$ & $\bigcirc$ & 0 & $\bigcirc$ & $\bigcirc$ \\
\hline
\end{tabular}

\section{Design Recommendations}

These results and levers allow for postulation of a variety of design recommendations, that when followed consequently have a high possibility of strengthening adhesion in multi-material parts by additive manufacturing. First some general requirements for utilization of a certain material combination by MEX and general influences on bonding strength are postulated. Then four design recommendations are given each with specific reasoning for why they improve bonding strength.

\subsection{General Requirements and General Influences}

Even though process settings have a huge influence on compatibility of material combinations some minimum requirements have to be fulfilled in order to be used in the same MEX process. All thermal requirements for both materials have to be able to be met in theory. Especially refractory deformation temperature of both materials may not be exceeded inside the build volume during the manufacturing process in order to maintain geometric accuracy of the part. If any material has a minimum requirement for build volume temperature that is exceeding the softening temperature of the other used material, this combination of materials is impossible to process. An example for this is the combination of PLA and PEEK. While the former has a softening temperature of about $60{ }^{\circ} \mathrm{C}$, 
the latter requires the build volume to be heated to at least $60^{\circ} \mathrm{C}$ in order to minimize warping and delamination, making the material combination not worthwhile.

In the same vein, material combinations may only be unsuitable in certain orientations or in certain parts of the build volume. Two materials may for example pose different requirements for the temperature or nature of the build plate that may be incompatible with each other. This means those materials can never be combined successfully in the first layer of the manufacturing process, while processability may be possible above a certain critical height, where the thermal influence of the build plate is below a critical value. Furthermore, those combinations can therefore never have a vertically oriented interface throughout the whole part, since this would require combination of both materials in every layer. However, horizontal or tilted interfaces may still be possible to produce.

Moreover, wettability is a crucial factor in compatibility of materials. As a minimal requirement for utilizing a certain material combination in the same process, wettability of one of the materials on the other needs to exceed a certain value. If the angle of contact is too big, the interface zone will inevitably fail, since only minor forces can be transmitted. This means that design measures like interlocking features have a chance to improve interface strength only if wettability is above a certain critical value.

On top of that, a variety of environmental factors has high influence on bonding strength. Those factors are not examined explicitly in this publication; however, their influence should be minimized as good as possible during the printing process. In order to increase bonding, humidity inside the build volume needs to be, as small as possible and temperature gradients as well as air currents need to be eliminated efficiently. Additionally, the used materials need to be free of moisture in order to ensure acceptable material behavior. Lastly, the tool change, i.e., the switching between different extruders during printing, needs to be such up in such a way to avoid contamination of the interface zone. Ideally, the script for the tool change includes steps for wiping clean the nozzle as well as retraction of filament, in order to avoid blemishing the interface zone by oozing.

\subsection{Reduction of Thermal Stresses}

In order to achieve high bonding strength, reduction of thermal stresses that might lead to small cracks or deformation of the interface is crucial. For this reason, the materials being used in the same process should show a small difference in the coefficient of linear thermal expansion.

If the difference is too high, thermal stresses induced into the interface while cooling may lead to failure of the produced component even without load or may significantly weaken the interface strength. Designing the component in such a way, that the interface shows high stiffness can partially counteract this phenomenon. Additionally, the direction of highest thermal contraction should be reinforced by design measures in order to avoid catastrophic failure. In the same vein, orientation of the infill pattern can lead to reduction of thermal stresses by stiffening the structure in direction of the highest thermal contraction.

On the other hand, thermal stresses can be eliminated by annealing the structure during printing. By holding high temperatures inside the printing volume for extended periods, thermal stresses are relieved and bonding strength is increased. If the used additive manufacturing machine has no encapsulated printing volume if the interface zone is in a low z-position, a similar effect can be achieved by increasing and holding printing bed temperature for some time. Slowly cooling the part inside the printing volume can further reduce thermal stresses and thereby increase interface strength.

\subsection{Enhancement of Diffusion}

In order to increase adhesion, diffusion needs to be accounted for. This means that diffusivity of materials plays a crucial role in achieving higher adhesion through diffusion theory. Apart from choosing highly diffusible material combinations, increased temperature leads to better interdiffusion of polymers in the interface zone, since Brownian motion of polymer chains drives diffusion. However, 
thermal diffusion coefficient decreases with increasing molar mass of the material, meaning longer polymer chains lead to a reduction in adhesion strength.

On the other hand, process parameters can be adjusted to increase energy input into the interface and thereby increasing interdiffusion. For example, by increasing nozzle temperature, reducing printing speed, line width, or layer height, the hot nozzle lingers longer at the interface all the while radiating thermal energy. This increases the driving force for diffusion and leads to better interface strength.

On top of that, leveling, i.e., the vertical distance of the two nozzles, plays an important role in achieving high interface strength. Lowering the second nozzle in respect to the first means, that the distance to the already printed part becomes smaller, leading to more energy being inserted into the interface zone. However, lowering the second nozzle below a certain critical height leads to clogging, especially when processing flexible materials. Therefore, careful adjustment of leveling is crucial.

\subsection{Mechanical Interlocking}

Mechanical interlocking generally increases interface strength and can be enhanced by several means. Firstly, surface topography plays an important role in surface strength. If surface roughness of the solid material is high and viscosity and surface tension of the liquid material are low enough to fill all crevices, resulting mechanical adhesion is high. However, if the crevices are too deep to be completely filled, higher roughness has no beneficial influence on interface strength anymore.

The mechanism of mechanical adhesion can furthermore be utilized deliberately by designing interlocking features that strengthen the interface. Since AM offers new geometric freedom compared to conventional manufacturing, interlocking features can be specifically designed to withstand certain load cases.

On top of that, process parameters like flow rate and nozzle temperature can increase mechanical interlocking. For example, by deliberately under extruding the last layer before the material change holes can be produced that could then be filled by excess material of the first layer after the material change. This means that the higher layer needs to be over extruded and the printing temperature needs to be increased, in order to be able to completely all generated holes. For this reason, infill pattern, line width, and leveling are expected to have influence on mechanical adhesion, since they adjust the prevalence and placement of such holes and interlocking features.

\subsection{Wettability}

Regarding wettability, polarity and surface energy of the two materials play an important role. Since high wettability generally means better adsorption and thereby better adhesion, the material combination should be chosen to be as compatible as possible. Since it is important which of the materials is applied onto the other in which order, the orientation of the interface inside the build volume needs to be considered, as well as the combination of materials.

Moreover, modification of surface chemistry and thereby polarity of the solid material, for example by plasma treatment, can lead to a significant increase in interface strength and should be considered strongly when the compatibility of materials is low.

\subsection{Decision Aid}

AM offers a multitude of possibilities for functional part design. However, these new potentials go hand in hand with a multitude of decisions that need to be made in part design as well as fabrication. It might not be clear to an unexperienced user how these decisions influence the outcome of the printing process, or more importantly, how they influence each other. For this reason, Figure 14 shows a concise overview of the decision making process for MMAM. 


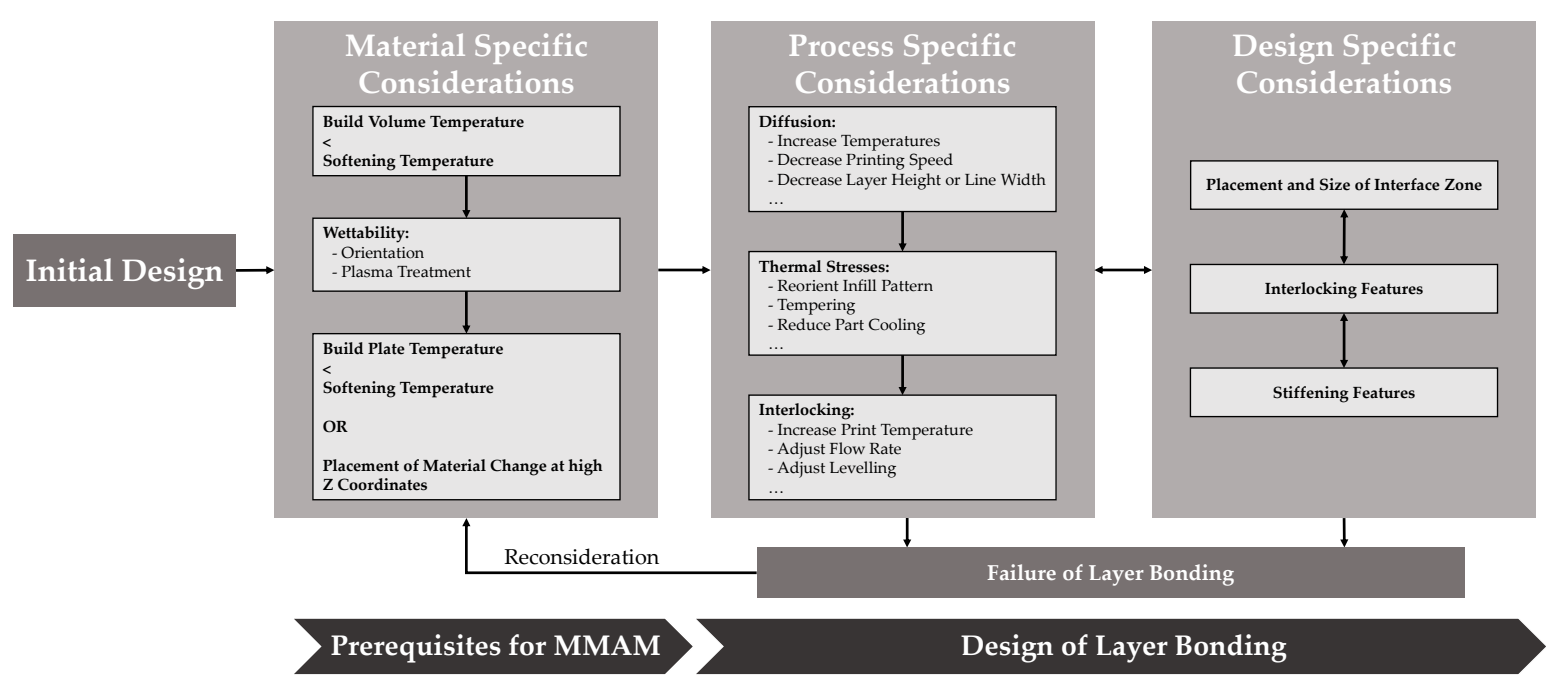

Figure 14. Proposed decision aid for designing of MMAM Parts.

Since prerequisites mainly depend on the used materials, material specific choices need to be the first step. Process parameters in turn depend on the used materials but require less effort than a redesign of the part. For this reason, they should be considered next. Only if an adjustment of the process does not lead to sufficient consider bonding strength, should a time consuming adjustment of the part design or a change in material choice. Better yet, consideration of process and material dependent limitation during the initial part design can drastically reduce the number of iterations and shorten time of development.

\section{Conclusions}

This publication presents a variety of design and process measures to improve interface strength of multi-material additive manufacturing parts. Based on custom-designed test specimen for peel resistance measurements a variety of rigid-flexible material combinations has been tested. Those test results are interpreted based on the underlying physical principle of adhesion and the most relevant influences on interface strength regarding material, process parameters, and pretreatment are derived systematically. Mechanical interlocking and polarity are shown to have major influence on the interface strength, but a multitude of other factors still influence bonding strength.

Based on these conclusions, design recommendations are postulated for multi-material additive manufacturing that lead to enhanced inter-material bonding and therefore better component properties. These recommendations act as decision aids for unexperienced AM users, in order to give aid in decision making during choice of materials, optimization of process parameters, as well as design for additive manufacturing. Overall, once general requirements are met, decisions should be made in such a way as to reduce thermal stresses as well as enhance wettability, diffusion and interlocking. These decisions may either appear during choice of process parameters and materials but should also find consideration during part design, as design choices like integration of interlocking features at the interface are shown to have significant benefit for achieving high interface strength.

Future work will focus on the utilization of design freedom offered by AM especially in regards to interlocking features. Figure 15 exemplarily shows the implementation of geometrically complex structures for combination of PP and ABS. In this instance, lattice-like structures are implemented to achieve material bonding. The impact of different geometric features is to be examined more thoroughly. 


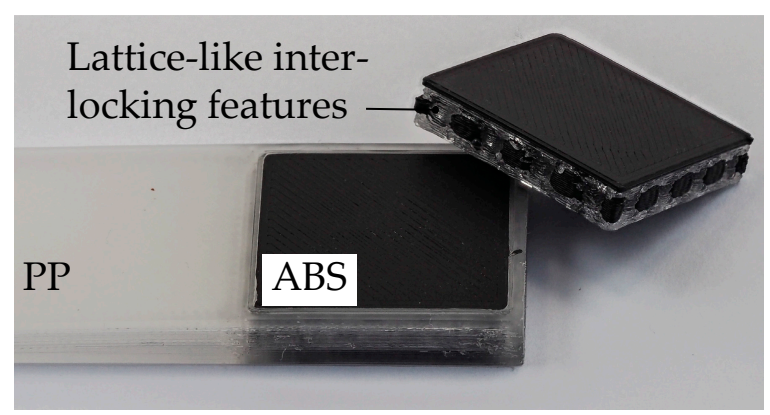

(a)

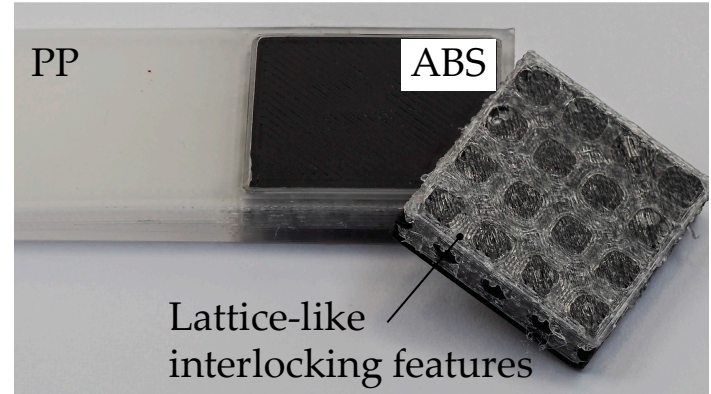

(b)

Figure 15. Side (a) and top view (b) of lattice-like interlocking features for combination of PP and ABS.

Furthermore, a more detailed method for further assistance in the process of decision making during choice of materials, fabrication as well as design of multi material AM parts is to be developed. Especially for complex tasks like integration of functions via local material variance. For inexperienced AM users, such a method may be highly beneficial. The presented work plays a major role in development of such a method.

Author Contributions: Conceptualization, H.W. and R.F.; methodology, H.W.; formal analysis, H.W. and R.F.; investigation, J.H., H.W. and R.F.; resources, T.V.; writing—original draft preparation, R.F.; writing-review and editing, H.W. and T.V.; visualization, H.W. and R.F.; supervision, T.V.; project administration, T.V.; funding acquisition, T.V.

Funding: This research received no external funding.

Acknowledgments: We acknowledge support by the German Research Foundation and the Open Access Publication Funds of the Technische Universität Braunschweig.

Conflicts of Interest: The authors declare no conflict of interest.

\section{References}

1. Rothe, S.; Blech, C.; Watschke, H.; Vietor, T.; Langer, S. Numerical modelling of additively manufactured acoustic black holes. In Proceedings of the Inter-Noise 2018 47th International Congress and Exposition on Noise Control Engineering, Chicago, IL, USA, 26-29 August 2018; pp. 2137-2148.

2. Ge, Q.; Sakhaei, A.H.; Lee, H.; Dunn, C.K.; Fang, N.X.; Dunn, M.L. Multimaterial 4D Printing with Tailorable Shape Memory Polymers. Sci. Rep. 2016, 6, 31110. [CrossRef] [PubMed]

3. Watschke, H.; Hilbig, K.; Vietor, T. Design and Characterization of Electrically Conductive Structures Additively Manufactured by Material Extrusion. Appl. Sci. 2019, 9, 779. [CrossRef]

4. Watschke, H.; Rautenberg, D.; Waalkes, L.; Junior, C.S.; Vietor, T. Integration of conductive functions based on Fused Layer Modeling. In Rapid.Tech-International Trade Show \& Conference for Additive Manufacturing: Proceedings of the 14th Rapid.Tech Conference, Erfurt, Germany, 20-22 June 2017; Kynast, M., Eichmann, M., Witt, G., Eds.; Hanser: München, Germany, 2017; pp. 419-432. ISBN 9783446454606.

5. Wu, J.; Yuan, C.; Ding, Z.; Isakov, M.; Mao, Y.; Wang, T.; Dunn, M.L.; Qi, H.J. Multi-shape active composites by 3D printing of digital shape memory polymers. Sci. Rep. 2016, 6, 24224. [CrossRef] [PubMed]

6. Gnanasekaran, K.; Heijmans, T.; van Bennekom, S.; Woldhuis, H.; Wijnia, S.; de With, G.; Friedrich, H. 3D printing of CNT- and graphene-based conductive polymer nanocomposites by fused deposition modeling. Appl. Mater. Today 2017, 9, 21-28. [CrossRef]

7. Ultimaker.com. Material Compatibility. Available online: https://ultimaker.com/en/resources/49799-materialcompatibility (accessed on 20 February 2019).

8. Awaja, F.; Gilbert, M.; Kelly, G.; Fox, B.; Pigram, P.J. Adhesion of polymers. Prog. Polym. Sci. 2009, 34, 948-968. [CrossRef]

9. Gibson, I.; Rosen, D.; Stucker, B. Additive manufacturing technologies. 3D printing, rapid prototyping and direct digital manufacturing, 2nd ed.; Springer: New York, NY, USA; Heidelberg, Germany; Dodrecht, The Netherlands; London, UK, 2015; ISBN 9781493921133. 
10. DIN Deutsches Institut für Normung e.V. Additive manufacturing-General Principles. In Terminology; Beuth Verlag GmbH: Berlin, Germany, 2018.

11. Watschke, H.; Waalkes, L.; Schumacher, C.; Vietor, T. Development of Novel Test Specimens for Characterization of Multi-Material Parts Manufactured by Material Extrusion. Appl. Sci. 2018, 8, 1220. [CrossRef]

12. Vaezi, M.; Chianrabutra, S.; Mellor, B.; Yang, S. Multiple material additive manufacturing-Part 1: A review. Virtual Phys. Prototyp. 2013, 8, 19-50. [CrossRef]

13. Oztan, C.; Ballikaya, S.; Ozgun, U.; Karkkainen, R.; Celik, E. Additive manufacturing of thermoelectric materials via fused filament fabrication. Appl. Mater. Today 2019, 15, 77-82. [CrossRef]

14. Yao, X.; Moon, S.K.; Bi, G.; Wei, J. A multi-material part design framework in additive manufacturing. Int. J. Adv. Manuf. Technol. 2018, 99, 2111-2119. [CrossRef]

15. Nagel, J.K.S.; Liou, F.W. Designing a Modular Rapid Manufacturing Process. J. Manuf. Sci. Eng. 2010, 132, 61006. [CrossRef]

16. Kumke, M.; Watschke, H.; Vietor, T. A new methodological framework for design for additive manufacturing. Virtual Phys. Prototyp. 2016, 11, 3-19. [CrossRef]

17. Wargnier, H.; Kromm, F.X.; Danis, M.; Brechet, Y. Proposal for a multi-material design procedure (1980-2015). Mater. Des. 2014, 56, 44-49. [CrossRef]

18. Schuck, M. Kompatibilitätsprinzipien beim Montagespritzgießen; Lehrstuhl für Kunststofftechnik: Erlangen, Germany, 2008; ISBN 978-3-931864-44-6.

19. Sun, Q.; Rizvi, G.M.; Bellehumeur, C.T.; Gu, P. Effect of processing conditions on the bonding quality of FDM polymer filaments. Rapid Prototyp. J. 2008, 14, 72-80. [CrossRef]

20. Wang, T.-M.; Xi, J.-T.; Jin, Y. A model research for prototype warp deformation in the FDM process. Int. J. Adv. Manuf. Technol. 2007, 33, 1087-1096. [CrossRef]

21. Mohamed, O.A.; Masood, S.H.; Bhowmik, J.L. Optimization of fused deposition modeling process parameters: A review of current research and future prospects. Adv. Manuf. 2015, 3, 42-53. [CrossRef]

22. Williams, M.L.; Landel, R.F.; Ferry, J.D. The Temperature Dependence of Relaxation Mechanisms in Amorphous Polymers and Other Glass-forming Liquids. J. Am. Chem. Soc. 1955, 77, 3701-3707. [CrossRef]

23. Kinloch, A.J. The science of adhesion. J. Mater. Sci. 1980, 15, 2141-2166. [CrossRef]

24. Fourche, G. An overview of the basic aspects of polymer adhesion. Part I: Fundamentals. Polym. Eng. Sci. 1995, 35, 957-967. [CrossRef]

25. Fourche, G. An overview of the basic aspects of polymer adhesion. Part II: Application to surface treatments. Polym. Eng. Sci. 1995, 35, 968-975. [CrossRef]

26. da Silva, L.F.M.; Öchsner, A.; Adams, R.D. Handbook of Adhesion Technology; Springer International Publishing: Cham, Germany, 2018; ISBN 978-3-319-55410-5.

27. Bruyne, N.A.D. The Physics of Adhesion. J. Sci. Instrum. 1947, 24, 29-35. [CrossRef]

28. Ebnesajjad, S. Theories of Adhesion. In Surface Treatment of Materials for adh!Esive Bonding, 2nd ed.; Ebnesajjad, S., Ebnesajjad, C.F., Eds.; William Andrew an imprint of Elsevier: Amsterdam, The Netherlands; Boston, MA, USA; Heidelberg, Germany, 2014; pp. 77-91. ISBN 9780323264358.

29. Noeske, M.; Degenhardt, J.; Strudthoff, S.; Lommatzsch, U. Plasma jet treatment of five polymers at atmospheric pressure: surface modifications and the relevance for adhesion. Int. J. Adhes. Adhes. 2004, 24, 171-177. [CrossRef]

30. Voyutskiŭ, S.S. The Diffusion Theory of Adhesion. Rubber Chem. Technol. 1960, 33, 748-756. [CrossRef]

31. Bikerman, J.J. CAUSES OF POOR ADHESION: WEAK BOUNDARY LAYERS. Ind. Eng. Chem. 1967, 59, 40-44. [CrossRef]

32. Roberts, A.D. Surface charge contribution in rubber adhesion and friction. J. Phys. D: Appl. Phys. 2001, 10, 1801. [CrossRef]

33. DIN Deutsches Institut für Normung e.V. Adhesives—Determination of Peel Resistance of Adhesive Bonds—Floating Roller Method; Beuth Verlag GmbH: Berlin, Germany, 2010.

34. Technical Data Sheet-NatureWork Ingeo ${ }^{\mathrm{TM}}$ Biopolymer 4043D. Available online: https: //www.natureworksllc.com/ \{\}/media/Files/NatureWorks/Technical-Documents/Technical-Data-Sheets/ TechnicalDataSheet_4043D_3D-monofilament_pdf.pdf?la=en (accessed on 10 January 2019).

35. Technical Data Sheet-ABS by Innofil3D BV, Version No.: 2.0. Available online: https://www.innofil3d.com/ wp-content/uploads/2016/05/TDS-Innofil3D-ABS-160609.pdf (accessed on 10 January 2019). 
36. Technical Data-XT-BLACK by colorFabb. Available online: https://colorfabb.com/xt-black (accessed on 1 January 2019).

37. Technical Data-XT-CF20 by colorFabb Produced with AMPHORA 3D Polymer from Eastman Chemical. Available online: https://colorfabb.com/xt-cf20 (accessed on 10 January 2019).

38. Technical Data Sheet-GF30-PA6 by XSTRAND ${ }^{\mathrm{TM}}$. Available online: https://dcpd6wotaa0mb.cloudfront.net/ mdms/dms/CSB/10022733/10022733-\%E2\%80\%93-XSTRAND\%E2\%84\%A2-3D-GF30-PA6-3D-Filamentglass-fiber-reinforced-polyamide-6.pdf?v=1520934344000 (accessed on 10 January 2019).

39. Technical Data Sheet-NinjaFlex@85A by NinjaTek. Available online: https://ninjatek.fppsites.com/wpcontent/uploads/2018/10/NinjaFlex-TDS.pdf (accessed on 10 January 2019).

40. Technical Data Sheet-TPU-93 by German RepRap. Available online: https://germanreprap.sharepoint. com/sites/partner/Documents/Forms/AllItems.aspx?id=\%2Fsites\%2Fpartner\%2FDocuments\%2FReseller\% 20Online\%20Portal\%2FProducts\%2FFilaments\%2FTPU93_TPU64D\%2FDatasheet\%2FTechnisches_

Datenblatt_TPU_93_Transparent_de\%2Epdf\&parent=\%2Fsites\%2Fpartner\%2FDocuments\%2FReseller\% 20Online\%20Portal\%2FProducts\%2FFilaments\%2FTPU93_TPU64D\%2FDatasheet\&p=true\&slrid= a9afb49e-b05d-7000-4514-86cba6a69bb2 (accessed on 10 January 2019).

(C) 2019 by the authors. Licensee MDPI, Basel, Switzerland. This article is an open access article distributed under the terms and conditions of the Creative Commons Attribution (CC BY) license (http://creativecommons.org/licenses/by/4.0/). 